\title{
Timing of changing therapy from gemcitabine and cisplatin chemotherapy based on real-world data of advanced urothelial carcinoma
}

\author{
NOBUKI FURUBAYASHI, TAKAHITO NEGISHI, DAI TAKAMATSU, KOSUKE IEIRI, \\ TOMOHIRO INOUE, KEIJI TSUKINO and MOTONOBU NAKAMURA \\ Department of Urology, National Hospital Organization Kyushu Cancer Center, Fukuoka 811-1395, Japan
}

Received July 16, 2019; Accepted January 21, 2020

DOI: $10.3892 / \mathrm{ol} .2020 .11368$

\begin{abstract}
Cisplatin-based systemic chemotherapy is the gold-standard approach for the first-line treatment of patients with advanced or metastatic urothelial carcinoma (UC). However, the optimal number of cycles is still unclear. The current study retrospectively assessed the clinical outcome in patients who received gemcitabine and cisplatin (GC) chemotherapy as first-line treatment for metastatic urothelial cancer to clarify the timing of switching from GC therapy. A total of 61 patients with locally advanced or metastatic UC who received first-line chemotherapy with GC were retrospectively reviewed at National Hospital Organization Kyushu Cancer Center between June 2009 and August 2017. The progression-free survival (PFS) and overall survival (OS) were evaluated using the Kaplan-Meier method. The significance of associations between the clinical parameters and OS was assessed using the Cox proportional hazards regression model. The median cycle number for GC chemotherapy was 4 . The median PFS and OS of all cases was 5.2 and 14.1 months, respectively. The multivariate analyses revealed that a neutrophil-to-lymphocyte ratio $\geq 3.0$ (hazard ratio $[\mathrm{HR}], 2.521,95 \%$ confidence interval $[\mathrm{CI}]=1.179-5.624$; $\mathrm{P}=0.017$ ) and best response to GC therapy of $\mathrm{CR}+\mathrm{PR}$ (HR 0.110 ; 95\% $\mathrm{CI}=0.028-0.411 ; \mathrm{P}<0.001)$ were independent prognostic factors. However, the number of GC cycles $(\leq 4$ vs. $>4)$ was not an independent prognostic factor $(\mathrm{P}=0.387)$. The current retrospective study indicated that changes to therapy should be considered at an early stage for cases with a therapeutic effect of SD or less, regardless of the number of GC therapy cycles.
\end{abstract}

Correspondence to: Dr Nobuki Furubayashi, Department of Urology, National Hospital Organization Kyushu Cancer Center, Notame 3-1-1, Minami-ku, Fukuoka 811-1395, Japan

E-mail: furubayashi-jua@umin.ac.jp

Key words: urothelial carcinoma, gemcitabine, cisplatin, pembrolizumab

\section{Introduction}

Urothelial carcinoma (UC) is the most common cancer of the bladder and upper urinary tract and is invasive and lethal, especially in advanced and metastatic patients $(1,2)$. Advanced UC patients generally have a poor prognosis, and only a few patients survive more than five years (3).

Pembrolizumab, a humanized monoclonal antibody that targets programmed death receptor-1, was associated with a significant overall survival (OS) benefit when compared with docetaxel, paclitaxel and vinflunine in the second-line treatment of metastatic UC in the Phase III trial KEYNOTE-045 (4). Since December 2017, pembrolizumab has been approved in Japan as a second-line treatment for radical unresectable UC that has become exacerbated after chemotherapy (5). However, cisplatin-based systemic chemotherapy is still the gold-standard approach for patients with advanced or metastatic UC in the first line (6-9). Combined chemotherapy with gemcitabine and cisplatin (GC) has been accepted as another standard treatment for advanced UC, as this therapy showed equivalent efficacy and less toxicity than combined chemotherapy of methotrexate, vinblastine, doxorubicin and cisplatin (MVAC) in a randomized phase 3 trial (10). However, there have been cases in which GC chemotherapy was continuously administered or re-administered because the optimum number of courses for GC chemotherapy has not been determined and no second-line standard therapy had been established before pembrolizumab was allowed to be used in Japan.

In the present study, we retrospectively assessed the clinical outcome in patients who received GC chemotherapy as first-line treatment for advanced or metastatic UC in order to clarify the timing of switching from GC chemotherapy.

\section{Materials and methods}

All of the patients provided their written informed consent to participate in this study, and the study protocol was approved by the Ethics Committee of the National Hospital Organization Kyushu Cancer Center (Fukuoka, Japan).

The patients with locally advanced or metastatic UC who received first-line chemotherapy with GC at our institution between June 2009 and August 2017 were retrospectively 
evaluated. UC was histopathologically diagnosed in all cases (11). In the GC regimen, gemcitabine $\left(1,000 \mathrm{mg} / \mathrm{m}^{2}\right)$ was administered intravenously on days 1,8 and 15 , and cisplatin $\left(70 \mathrm{mg} / \mathrm{m}^{2}\right)$ were administered intravenously on day 2 . The cycle was basically repeated every 28 days (7). Cisplatin dose reduction was based on the estimated glomerular filtration rate (eGFR); the cisplatin dose was reduced to $75 \%$ when the eGFR was $46-60 \mathrm{ml} / \mathrm{min} / 1.73 \mathrm{~m}^{2}$ and to $50 \%$ when the eGFR was $30-45 \mathrm{ml} / \mathrm{min} / 1.73 \mathrm{~m}^{2}$. When the eGFR was $<30 \mathrm{ml} / \mathrm{min} / 1.73 \mathrm{~m}^{2}$, cisplatin administration was basically prohibited $(12,13)$.

Decisions regarding adverse events were made based on the Common Terminology Criteria for Adverse Events, version 4.0 (14). If Grade $\geq 2$ adverse events were observed, dose reduction of GC chemotherapy was performed to ensure that adverse events were grade $\leq 1$ in the next cycle. The GC regimen was repeated until disease progression or unacceptable adverse events occurred. Tumor measurements were generally performed by computed tomography before and after every two to three cycles. The tumor response was evaluated as the best response according to the Response Evaluation Criteria In Solid Tumors, version 1.1 (15). The overall response rate is defined as the proportion of patients who achieve a partial or complete response to GC chemotherapy.

Statistical analysis. Statistical analyses were performed using the JMP ${ }^{\circledR}$ Pro, version 12.2.0, software package (SAS Institute, Inc.). The OS was calculated from the day on which chemotherapy was started until the date of the last follow-up examination or death from any cause. The progression-free survival (PFS) and OS were evaluated using the Kaplan-Meier method, and the log-rank test was used to determine differences in the PFS and OS among the primary tumor site groups. The significance of associations between the clinical parameters and OS was assessed using the Cox proportional hazards regression model. $\mathrm{P}<0.05$ was considered to indicate a statistically significant difference.

\section{Results}

Patients' characteristics. The clinical characteristics of the 61 patients (male, $\mathrm{n}=42$; female, $\mathrm{n}=19$; median age, 69 years; range, 49-86 years) are listed in Table I. All of the patients received GC as the first-line chemotherapy for advanced or metastatic UC. Thirty patients had upper urinary tract UC, 25 had bladder UC, and 6 had both types of UC. Thirty patients (49.2\%) had visceral metastasis. The cisplatin dose was reduced in 31 patients $(50.1 \%)$ due to renal dysfunction from the initial cycle administration. The median cycle number for GC chemotherapy was 4 (range, 1-13).

The PFS of all cases and according to the primary tumor site. The PFS of all cases and according to the primary tumor site is shown in Fig. 1. The median PFS of all cases was 5.2 months (95\% confidence interval [CI], 3.7-7.5 months). The median PFS for upper urinary tumors was 5.7 months $(95 \% \mathrm{CI}$, 4.8-8.4 months), that for bladder tumors was 3.7 months (95\% CI, 2.3-7.5 months), and that for cases with both tumors was 3.3 months (95\% CI, 0.6-10.4). There was no significant difference in the PFS among the 3 tumor site groups $(\mathrm{P}=0.132)$.
Table I. Patients' characteristics.

\begin{tabular}{|c|c|}
\hline Characteristics $(\mathrm{n}=61)$ & Number of patien \\
\hline \multicolumn{2}{|l|}{ Sex } \\
\hline Male & 42 \\
\hline Female & 19 \\
\hline \multicolumn{2}{|l|}{ Age, years } \\
\hline Median (range) & $69(49-86)$ \\
\hline \multicolumn{2}{|l|}{ ECOG PS } \\
\hline 0 & 31 \\
\hline 1 & 26 \\
\hline$\geq 2$ & 4 \\
\hline \multicolumn{2}{|l|}{ Anemia $(\mathrm{Hb}<10 \mathrm{~g} / \mathrm{dl})$} \\
\hline Yes & 8 \\
\hline No & 53 \\
\hline \multicolumn{2}{|l|}{ CRP (mg/dl) } \\
\hline$<0.3$ & 15 \\
\hline$\geq 0.3$ & 46 \\
\hline \multicolumn{2}{|l|}{ Albumin $(\mathrm{g} / \mathrm{dl})$} \\
\hline$\geq 4.0$ & 18 \\
\hline$<4.0$ & 43 \\
\hline \multicolumn{2}{|l|}{ NLR } \\
\hline Median (range) & $2.9(0.7-17.3)$ \\
\hline \multicolumn{2}{|l|}{ Primary tumor site } \\
\hline Bladder & 25 \\
\hline Upper urinary tract & 30 \\
\hline Bladder + upper urinary tract & 6 \\
\hline \multicolumn{2}{|l|}{ Clinical tumor classification } \\
\hline $\mathrm{Ta}$ & 1 \\
\hline $\mathrm{T} 1$ & 6 \\
\hline $\mathrm{T} 2$ & 15 \\
\hline $\mathrm{T} 3$ & 26 \\
\hline $\mathrm{T} 4$ & 13 \\
\hline
\end{tabular}

Histologic grade

G1

0

G2

15

G3

41

Unknown

Histology

Pure UC

Mixed UC

Surgical treatment for the primary tumor

Cystectomy

Cystectomy + nephroureterectomy

5

Nephrouureterectomy

21

Transurethral resection

12

Visceral metastasis

Negative

31

Positive

30

Cisplatin dose reduction from initial

administration

Yes

31

No

30

ECOG PS, Eastern Cooperative Oncology Group Performance Status; CRP, C-reactive protein; NLR, neutrophil/lymphocyte ratio; UC, urothelial carcinoma. 

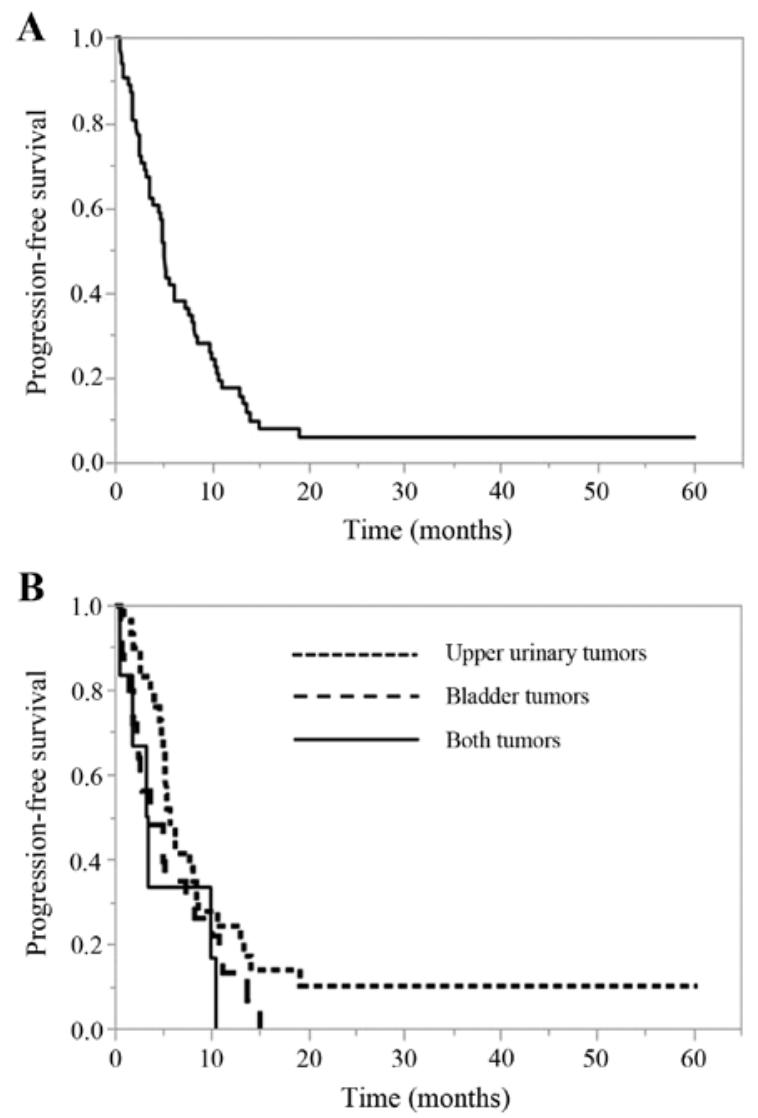

Figure 1. PFS (months). (A) All cases. (B) According to the primary tumor site. PFS, progression-free survival.

The OS of all cases and according to the primary tumor site. The OS of all cases and according to the primary tumor site is shown in Fig. 2. The median OS of all cases was 14.1 months (95\% CI, 10.7-19.3 months). The median OS for upper urinary tumors was 17.2 months (95\% CI, 10.8-36.9 months), that for bladder tumors was 11.2 months (95\% CI, 7.5-15.2 months), and that for cases with both tumors was 8.3 months (95\% CI, 1.9-36.2). There was no significant difference in the OS among the 3 tumor site groups $(\mathrm{P}=0.157)$.

The response analysis in patients who received GC chemotherapy. The objective tumor responses are shown in Table II. Among the 61 patients, a complete response (CR) was confirmed in 7 patients $(11.5 \%)$, while $20(32.8 \%)$ showed a partial response (PR), with an overall response rate of $44.3 \%$.

Univariate and multivariate analyses of the associations between various factors and the OS with GC chemotherapy. To identify the prognostic factors associated with the OS with GC chemotherapy, univariate and multivariate analyses using the Cox proportional hazards model were performed (Table III). Univariate analyses for various factors revealed that history of nephrectomy, the Eastern Cooperative Oncology Group Performance Status, the neutrophil-to-lymphocyte ratio (NLR), presence of visceral metastasis, presence of cisplatin dose reduction from initial administration, number of GC cycles, and best response to GC chemotherapy were prognostic variables. The multivariate analyses revealed that
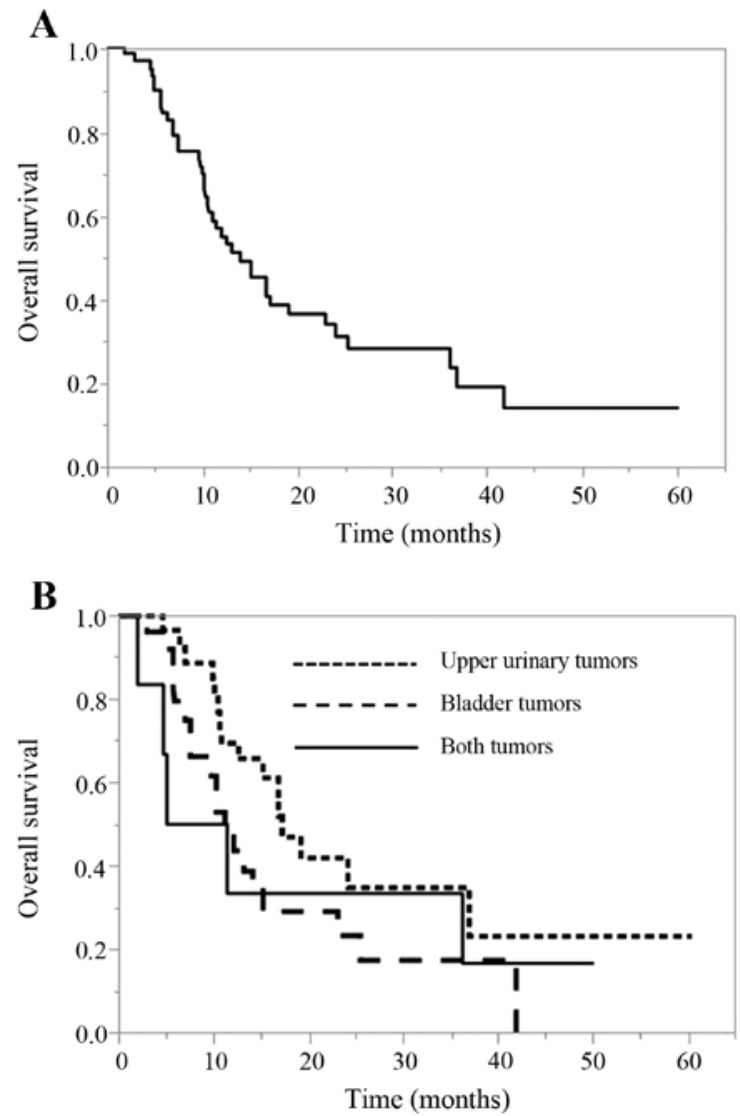

Figure 2. OS (months). (A) All cases. (B) According to the primary tumor site. OS, overall survival.

an NLR $\geq 3.0$ (hazard ratio [HR], 2.521, 95\% CI=1.179-5.624, $\mathrm{P}=0.017)$ and a best response to GC chemotherapy of $\mathrm{CR}+\mathrm{PR}$ (HR 0.110, 95\% CI=0.028-0.411, $\mathrm{P}<0.001$ ) were independent prognostic factors. However, the number of GC cycles was not an independent prognostic factor $(\mathrm{P}=0.387)$.

\section{Discussion}

Cisplatin-based systemic chemotherapy is the gold-standard approach for treating patients with advanced or metastatic UC $(16,17)$. However, randomized trials to determine the optimal number of cycles have not yet been performed. In addition, a standard second-line therapy had not been established in Japan for a long time before the relatively recent approval of pembrolizumab. Therefore, there were cases in which GC chemotherapy was continuously administered until disease progression or re-administered if a long time had passed since the last GC chemotherapy session.

Immune checkpoint inhibitors have greatly improved the survival of patients with several cancers (18-22). The PD-1 and PD-L1 inhibitors atezolizumab and pembrolizumab were approved for advanced UC by the United States Food and Drug Administration and the European Medicines Agency (23-26). Since December 2017, only pembrolizumab has been approved in Japan as a second-line treatment for radical unresectable UC that has become exacerbated after chemotherapy. Pembrolizumab was found to be associated with a significant OS benefit in second-line therapy for advanced or metastatic 
Table II. The analysis of the responses of patients who received GC chemotherapy.

\begin{tabular}{lcc}
\hline Response & $\begin{array}{c}\text { Number of } \\
\text { patients }\end{array}$ & $\begin{array}{c}\text { Response } \\
\text { rate (\%) }\end{array}$ \\
\hline CR & 7 & 11.5 \\
PR & 20 & 32.8 \\
SD & 20 & 32.8 \\
PD & 14 & 22.9 \\
Overall response rate & 27 & 44.3 \\
(CR+PR) & & \\
\hline
\end{tabular}

$\mathrm{CR}$, complete response; $\mathrm{PR}$, partial response; $\mathrm{SD}$, stable disease; $\mathrm{PD}$, progressive disease; GC, gemcitabine and cisplatin.

UC in the Phase III trial KEYNOTE-045 (4). In the present study, we retrospectively assessed the clinical outcome in patients who received GC chemotherapy as first-line treatment for advanced or metastatic UC in order to clarify the proper timing of switching from GC chemotherapy, with the aim of improving the efficacy of subsequent pembrolizumab administration.

A previous study reported that the median PFS in patients with locally advanced or metastatic UC who receive cisplatin-based first-line treatment ranges from 7.7 to 8.3 months, and the median OS ranges from 14.0 to 15.2 months (6). In the present study, the median PFS and OS of all cases was 5.2 and 14.1 months, respectively (Figs. 1 and 2), and neither of these rates is satisfactory.

To identify the prognostic factors associated with the OS with GC chemotherapy, univariate and multivariate analyses using the Cox proportional hazards model were performed (Table III). The multivariate analyses revealed that the pretreatment factor NLR $\geq 3.0$ (HR, 2.521, 95\% CI=1.179-5.624, $\mathrm{P}=0.017)$ and the posttreatment factor best response to $\mathrm{GC}$ therapy of CR+PR (HR 0.110, 95\% CI=0.028-0.411, $\mathrm{P}<0.001)$ were independent prognostic factors. However, the number of GC cycles was not an independent prognostic factor $(\mathrm{P}=0.387)$. These findings suggest that regardless of the number of cycles of GC chemotherapy, changes to therapy should be considered at an early stage for cases with a therapeutic effect of stable disease (SD) or less. In upper urinary tract UC, the cisplatin dose was reduced in 17 patients $(56.7 \%)$ due to renal dysfunction after the initial cycle administration. The median number of cycles for GC chemotherapy was 4 (range, 2-10). According to the objective tumor responses, a complete response (CR) was confirmed in 6 patients (20.0\%), while 8 (26.7\%) showed a partial response (PR), with an overall response rate of $46.7 \%$. In the present study, these results (rate of cisplatin reduction, cycle number and overall response rate) for upper urinary tract UC were similar to those of all cases.

A previous retrospective study reported that four cycles of platinum-based first-line chemotherapy appeared adequate for treating advanced UC and did not significantly compromise the survival of these patients (27). A prospective study of the ongoing phase III FOCUS trial in South Korea to determine the optimal duration of chemotherapy in patients with advanced
UC showed a non-inferior OS between four and six cycles of first-line cisplatin-based chemotherapy (https://clinicaltrials. gov/ct2/show/NCT03296306). Further results of that study are awaited. In addition, clinical investigations of second-line switching maintenance therapy with PD-1 or PD-L1 inhibitors in patients with stable but responding disease after first-line therapy are ongoing. Such trials, including a Study of Avelumab in Patients with Locally Advanced or Metastatic Urothelial Cancer (JAVELIN Bladder 100) (https://clinicaltrials. gov/ct2/show/NCT02603432) and Testing the PD-1 Inhibitor Pembrolizumab as Maintenance Therapy after Initial Chemotherapy in Metastatic Bladder Cancer (https:// clinicaltrials.gov/ct2/show/NCT02500121), have required at least 4 and not 6 cycles of prior platinum-based chemotherapy. Furthermore, the purpose of the ongoing KEYNOTE-361 is to determine the efficacy and safety of pembrolizumab with or without chemotherapy vs. chemotherapy alone in participants with advanced or metastatic UC (https://clinicaltrials. gov/ct2/show/NCT02853305). Depending on the results of these trials, the treatment policy for advanced or metastatic UC may change significantly in the future.

The omission of excessive cycles may avoid unnecessary cumulative toxicity and facilitate a better transition to second-line therapy and investigational switching maintenance therapy strategies. Notably, however, the number of GC cycles was not an independent prognostic factor in the present study (number of $\mathrm{GC}$ cycles $\leq 4$ vs. $>4, \mathrm{P}=0.387$ ). We therefore believe that four cycles of platinum-based first-line chemotherapy for advanced UC is adequate. Cisplatin in particular is associated with significant cumulative toxicity, especially neuropathy, venous thromboembolism and renal dysfunction, which may be irreversible and sometimes lethal, rendering it challenging to deliver the full course of six cycles of treatment $(28,29)$. Patients who tolerate the therapy better may receive more cycles and, consequently, experience better outcomes than less-tolerant patients. However, we were unable to identify such an association in this study, although this confounding factor would bias the analysis in favor of more cycles.

In reports of patients with other cancer type, chemotherapy has demonstrated an excellent response after exposure to immune checkpoint inhibitors $(30,31)$. Chemotherapies have been shown to exert immune-reactive effects, such as the upregulation of MHC class molecules or tumor antigens, causing an increase in tumor antigen presentation $(32,33)$, and these effects are theoretically beneficial for the immunotherapeutic strategies.

On the other hand, chemotherapies have also been shown to decrease the number of immunosuppressive cells in the tumor microenvironment, such as regulatory $\mathrm{T}$ cells and myeloid-derived suppressor cells, thereby increasing the helper T-cell accumulation at the tumor site $(34,35)$. This may be one reason why chemotherapy is effective after immune checkpoint inhibitor therapy. These results also suggest that it is better to change the regimen when appropriate, regardless of the number of first-line chemotherapy cycles, as part of sequence treatment.

The pretreatment NLR was also an independent prognostic factor in the present study (cut-off value $\geq 3.0, \mathrm{HR}, 2.521$, 95\% CI=1.179-5.624, P=0.017) (Table III). Previous systemic reviews and meta-analyses have found the NLR to be a prognostic indicator in the upper urinary tract and bladder (36-38). 
Table III. The univariate and multivariate analyses of the factors associated with OS in patients receiving GC chemotherapy.

\begin{tabular}{|c|c|c|c|c|}
\hline \multirow[b]{2}{*}{ Variables } & \multicolumn{2}{|c|}{ Univariate } & \multicolumn{2}{|c|}{ Multivariate } \\
\hline & $\mathrm{HR}(95 \% \mathrm{CI})$ & P-value & $\mathrm{HR}(95 \% \mathrm{CI})$ & P-value \\
\hline \multicolumn{5}{|l|}{ Age (years) } \\
\hline$<70$ & 1 & & & \\
\hline$\geq 70$ & $1.029(0.539-1.922)$ & 0.929 & & \\
\hline \multicolumn{5}{|l|}{ Sex } \\
\hline Male & 1 & & & \\
\hline Female & $0.658(0.305-1.305)$ & 0.239 & & \\
\hline \multicolumn{5}{|l|}{ Primary tumor site } \\
\hline Bladder & 1 & & & \\
\hline Upper urinary tract & $0.533(0.269-1.039)$ & 0.065 & & \\
\hline Bladder + upper urinary tract & $0.917(0.298-2.335)$ & 0.866 & & \\
\hline \multicolumn{5}{|l|}{ Histology } \\
\hline Pure UC & 1 & & & \\
\hline Mixed UC & $0.982(0.4800-1.891)$ & 0.959 & & \\
\hline \multicolumn{5}{|l|}{ ECOG PS } \\
\hline 0 & 1 & & 1 & \\
\hline$\geq 1$ & $2.976(1.552-5.944)$ & 0.001 & $1.543(0.682-3.598)$ & 0.301 \\
\hline \multicolumn{5}{|l|}{ Anemia $(\mathrm{Hb}<10 \mathrm{~g} / \mathrm{dl})$} \\
\hline Negative & 1 & & & \\
\hline Positive & $1.679(0.715-3.498)$ & 0.218 & & \\
\hline \multicolumn{5}{|l|}{ NLR } \\
\hline$<3.0$ & 1 & & 1 & \\
\hline$\geq 3.0$ & $2.143(1.142-4.129)$ & 0.018 & $2.521(1.179-5.624)$ & 0.017 \\
\hline \multicolumn{5}{|l|}{ Albumin $(\mathrm{g} / \mathrm{dl})$} \\
\hline$\geq 4.0$ & 1 & & & \\
\hline$<4.0$ & $1.560(0.801-3.270)$ & 0.197 & & \\
\hline \multicolumn{5}{|l|}{$\mathrm{CRP}(\mathrm{mg} / \mathrm{dl})$} \\
\hline$<0.3$ & 1 & & & \\
\hline$\geq 0.3$ & $1.536(0.743-3.588)$ & 0.259 & & \\
\hline \multicolumn{5}{|l|}{ Local excision surgery } \\
\hline Positive & 1 & & & \\
\hline Negative & $1.386(0.695-2.667)$ & 0.345 & & \\
\hline \multicolumn{5}{|l|}{ Best response to GC therapy } \\
\hline $\mathrm{PD}$ & 1 & & 1 & \\
\hline $\mathrm{SD}$ & $0.266(0.117-0.611)$ & 0.002 & $0.414(0.164-1.035)$ & 0.059 \\
\hline $\mathrm{CR}+\mathrm{PR}$ & $0.129(0.054-0.308)$ & $<0.001$ & $0.110(0.028-0.411)$ & $<0.001$ \\
\hline \multicolumn{5}{|l|}{$\begin{array}{l}\text { Cisplatin dose reduction from } \\
\text { initial administration }\end{array}$} \\
\hline Negative & 1 & & 1 & \\
\hline Positive & $1.996(1.065-3.845)$ & 0.031 & $1.831(0.936-3.667)$ & 0.077 \\
\hline \multicolumn{5}{|l|}{ No. GC cycles } \\
\hline$\leq 4$ & 1 & & 1 & \\
\hline$>4$ & $0.448(0.229-0.844)$ & 0.013 & $1.565(0.572-4.472)$ & 0.387 \\
\hline \multicolumn{5}{|l|}{ Visceral metastases } \\
\hline Negative & 1 & & 1 & \\
\hline Positive & $2.171(1.141-4.268)$ & 0.018 & $0.997(0.453-2.255)$ & 0.994 \\
\hline
\end{tabular}

OS, overall survival; UC, urothlial carcinoma; ECOG PS, Eastern Cooperative Oncology Group Performance Status; NLR, neutrophil/lymphocyte ratio; CRP, C-reactive protein; GC, gemcitabine and cisplatin; PD, progressive disease; SD, stable disease; CR, complete response; PR, partial response. 
The NLR can be easily determined from a full blood count and can potentially function as a simple and inexpensive assessment of the cancer prognosis, but the optimal cut-off value for the NLR remains to be established (39). In addition, the NLR is a dynamic marker, varying across time points during a patient's treatment course. Although the NLR alone should not be used to justify changing the treatment strategy, regimen changes should be considered at an early stage while also taking the NLR into consideration. Of note, a high NLR has also been associated with a poor outcome across studies, even in immune checkpoint inhibitor-treated patients (40).

As with similar previous studies, our study is limited by its retrospective nature and its analysis of a limited number of cases in a single institution. Confirmatory studies with larger populations may be required.

In conclusion, these real-world findings indicate that regardless of the number of cycles of GC chemotherapy for advanced or metastatic UC, changes to the therapy should be considered at an early stage for cases with a poor therapeutic effect (SD or less). Future clinical trials will be needed in order to determine the optimal number of GC chemotherapy courses.

\section{Acknowledgements}

Not applicable.

\section{Funding}

No funding was received.

\section{Availability of data and materials}

All data generated or analyzed during the present study are included in this published article.

\section{Authors' contributions}

NF, TN and MN designed the study. DT and KI extracted the data. DT, KI, TI and KT assisted with the data processing and statistical analysis. NF and MN wrote the article. TN and MN supervised the study and critically reviewed the manuscript. All authors have read and approved the final version of the manuscript.

\section{Ethics approval and consent to participate}

The present case report was approved by the Institutional Review Board of National Hospital Organization Kyushu Cancer Center (2014-99), and written informed consent was obtained from the patient.

\section{Patient consent for publication}

The patient provided written informed consent for the publication of any associated data.

\section{Competing interests}

The authors declare that they have no competing interests.

\section{References}

1. Lin T, Liu Z, Liu L, Yang L, Han P, Zhang P and Wei Q: Prospective evaluation of fluorescence in situ hybridization for diagnosing urothelial carcinoma. Oncol Lett 13: 3928-3934, 2017.

2. Niegisch G, Gerullis H, Lin SW, Pavlova J, Gondos A, Rudolph A Haas G, Hennies N and Kramer MW: A real-world data study to evaluate treatment patterns, clinical characteristics and survival outcomes for first- and second-line treatment in locally advanced and metastatic urothelial cancer patients in Germany. J Cancer 9: 1337-1348, 2018.

3. Nakagawa T, Taguchi S, Kanatani A, Kawai T, Ikeda M, Urakami S, Matsumoto A, Komemushi Y, Miyakawa J, Yamada D, et al: Oncologic outcome of metastasectomy for urothelial carcinoma: Who is the best candidate? Ann Surg Oncol 24: 2794-2800, 2017.

4. Bellmunt J, de Wit R, Vaughn DJ, Fradet Y, Lee JL, Fong L, Vogelzang NJ, Climent MA, Petrylak DP, Choueiri TK, et al: Pembrolizumab as second-line therapy for advanced urothelial carcinoma. N Engl J Med 376: 1015-1026, 2017.

5. Yuasa T, Urakami S and Yonese J: Recent advances in medical therapy for metastatic urothelial cancer. Int J Clin Oncol 23: 599-607, 2018.

6. von der Maase H, Sengelov L, Roberts JT, Ricci S, Dogliotti L, Oliver T, Moore MJ, Zimmermann A and Arning M: Long-term survival results of a randomized trial comparing gemcitabine plus cisplatin, with methotrexate, vinblastine, doxorubicin, plus cisplatin in patients with bladder cancer. J Clin Oncol 23: 4602-4608, 2005.

7. Sternberg CN, de Mulder P, Schornagel JH, Theodore C, Fossa SD, van Oosterom AT, Witjes JA, Spina M, van Groeningen CJ, Duclos B, et al: Seven year update of an EORTC phase III trial of high-dose intensity M-VAC chemotherapy and G-CSF versus classic M-VAC in advanced urothelial tract tumours. Eur J Cancer 42: 50-54, 2006.

8. Saxman SB, Propert KJ, Einhorn LH, Crawford ED, Tannock I, Raghavan D, Loehrer PJ Sr and Trump D: Long-term follow-up of a phase III intergroup study of cisplatin alone or in combination with methotrexate, vinblastine, and doxorubicin in patients with metastatic urothelial carcinoma: A cooperative group study. J Clin Oncol 15: 2564-2569, 1997.

9. Bellmunt J, von der Maase H, Mead GM, Skoneczna I, De Santis M, Daugaard G, Boehle A, Chevreau C, Paz-Ares L, Laufman LR, et al: Randomized phase III study comparing paclitaxel/cisplatin/gemcitabine and gemcitabine/cisplatin in patients with locally advanced or metastatic urothelial cancer without prior systemic therapy: EORTC intergroup study 30987. J Clin Oncol 30: 1107-1113, 2012.

10. von der Maase H, Hansen SW, Roberts JT, Dogliotti L, Oliver T, Moore MJ, Bodrogi I, Albers P, Knuth A, Lippert CM, et al: Gemcitabine and cisplatin versus methotrexate, vinblastine, doxorubicin, and cisplatin in advanced or metastatic bladder cancer: Results of a large, randomized, multinational, multicenter, phase III study. J Clin Oncol 18: 3068-3077, 2000.

11. Moch H, Cubilla AL, Humphrey PA, Reuter VE and Ulbright TM: The 2016 WHO classification of tumours of the urinary system and male genital organs-part A: Renal, penile and testicular tumours. Eur Urol 70: 93-105, 2016.

12. Merchan JR: Chemotherapy-related nephrotoxicity and dose modification $\mathrm{n}$ patients with renal insufficiency. In: UpToDate, Post TW (Ed). UpToDate, 2016.

13. The Japanese Society of Nephrology and Pharmacotherapy. http://jsnp.org/. Accessed July 15, 2019.

14. http://ctep.cancer.gov/protocolDevelopment/electronic_applications/ctc.htm\#ctc_40

15. Eisenhauer EA, Therasse P, Bogaerts J, Schwartz LH, Sargent D, Ford R, Dancey J, Arbuck S, Gwyther S, Mooney M, et al: New response evaluation criteria in solid tumours: Revised RECIST guideline (version 1.1). Eur J Cancer 45: 228-247, 2009.

16. National Comprehensive Cancer Network: Guidelines on bladder cancer. 2019 Jun 1; Accessed https://www.nccn.org/professionals/physician_gls/pdf/bladder.pdf.

17. European Association of Urology: Guidelines on bladder cancer. 2019 Jun 1; Accessed https://uroweb.org/guideline/bladder-cancer-muscle-invasive-and-metastatic/.

18. Hodi FS, O'Day SJ, McDermott DF, Weber RW, Sosman JA, Haanen JB, Gonzalez R, Robert C, Schadendorf D, Hassel JC, et al: Improved survival with ipilimumab in patients with metastatic melanoma. N Engl J Med 363: 711-723, 2010. 
19. Larkin J, Chiarion-Sileni V, Gonzalez R, Grob JJ, Cowey CL, Lao CD, Schadendorf D, Dummer R, Smylie M, Rutkowski P, et al: Combined nivolumab and ipilimumab or monotherapy in untreated melanoma. N Engl J Med 373: 23-34, 2015.

20. Brahmer J, Reckamp KL, Baas P, Crinò L, Eberhardt WE, Poddubskaya E, Antonia S, Pluzanski A, Vokes EE, Holgado E, et al: Nivolumab versus Docetaxel in advanced squamous-cell non-small-cell lung cancer. N Engl J Med 373: 123-135, 2015.

21. Borghaei H, Paz-Ares L, Horn L, Spigel DR, Steins M, Ready NE, Chow LQ, Vokes EE, Felip E, Holgado E, et al: Nivolumab versus Docetaxel in advanced nonsquamous non-small-cell lung cancer. N Engl J Med 373: 1627-1639, 2015.

22. Motzer RJ, Escudier B, McDermott DF, George S, Hammers HJ, Srinivas S, Tykodi SS, Sosman JA, Procopio G, Plimack ER, et al: Nivolumab versus everolimus in advanced renal-cell carcinoma. N Engl J Med 373: 1803-1813, 2015.

23. De Santis M, Bellmunt J, Mead G, Kerst JM, Leahy M, Maroto P, Gil T, Marreaud S, Daugaard G, Skoneczna I, et al: Randomized phase II/III trial assessing gemcitabine/carboplatin and methotrexate/carboplatin/vinblastine in patients with advanced urothelial cancer who are unfit for cisplatin-based chemotherapy: EORTC study 30986. J Clin Oncol 30: 191-196, 2012.

24. BalarAV,GalskyMD, Rosenberg JE,Powles T,PetrylakDP,BellmuntJ, Loriot Y, Necchi A, Hoffman-Censits J, Perez-Gracia JL, et al: Atezolizumab as first-line treatment in cisplatin-ineligible patients with locally advanced and metastatic urothelial carcinoma: A single-arm, multicentre, phase 2 trial. Lancet 389: 67-76, 2017.

25. Balar AV, Castellano D, O'Donnell PH, Grivas P, Vuky J, Powles T, Plimack ER, Hahn NM, de Wit R, Pang L, et al: First-line pembrolizumab in cisplatin-ineligible patients with locally advanced and unresectable or metastatic urothelial cancer (KEYNOTE-052): A multicentre, single-arm, phase 2 study. Lancet Oncol 18: 1483-1492, 2017.

26. Galsky MD, Hahn NM, Rosenberg J, Sonpavde G, Hutson T, Oh WK, Dreicer R, Vogelzang N, Sternberg CN, Bajorin DF and Bellmunt J: Treatment of patients with metastatic urothelial cancer 'unfit' for Cisplatin-based chemotherapy. J Clin Oncol 29: 2432-2438, 2011.

27. Sonpavde GP, Mariani L, Lo Vullo S, Raggi D, Giannatempo P, Bamias A, Crabb SJ, Bellmunt J, Yu EY, Niegisch G, et al: Impact of the number of cycles of platinum based first line chemotherapy for advanced urothelial carcinoma. J Urol 200: 1207-1214, 2018.

28. Chovanec M, Abu Zaid M, Hanna N, El-Kouri N, Einhorn LH and Albany C: Long-term toxicity of cisplatin in germ-cell tumor survivors. Ann Oncol 28: 2670-2679, 2017

29. Seng S, Liu Z, Chiu SK, Proverbs-Singh T, Sonpavde G, Choueiri TK, Tsao CK, Yu M, Hahn NM, Oh WK and Galsky MD: Risk of venous thromboembolism in patients with cancer treated with Cisplatin: A systematic review and meta-analysis. J Clin Oncol 30: 4416-4426, 2012.

30. Dwary AD, Master S, Patel A, Cole C, Mansour R, Mills G, Koshy N, Peddi P, Burton G, Hammoud D and Beedupalli K: Excellent response to chemotherapy post immunotherapy. Oncotarget 8: 91795-91802, 2017.
31. Alsuwaigh R, Lee J, Chan G, Chee CE and Choo SP: Response to targeted therapy or chemotherapy following immunotherapy in patients with gastrointestinal cancers-a case series. J Immunother Cancer 27: 162, 2019.

32. Ohtsukasa S, Okabe S, Yamashita H, Iwai $\mathrm{T}$ and Sugihara K: Increased expression of CEA and MHC class I in colorectal cancer cell lines exposed to chemotherapy drugs. J Cancer Res Clin Oncol 129: 719-726, 2003.

33. Wan S, Pestka S, Jubin RG, Lyu YL, Tsai YC and Liu LF: Chemotherapeutics and radiation stimulate MHC class I expression through elevated interferon-beta signaling in breast cancer cells. PLoS One 7: e32542, 2012.

34. Suzuki E, Kapoor V, Jassar AS, Kaiser LR and Albelda SM: Gemcitabine selectively eliminates splenic Gr-1+/CD11b+ myeloid suppressor cells in tumor-bearing animals and enhances antitumor immune activity. Clin Cancer Res 11: 6713-6721, 2005.

35. Ghiringhelli F, Larmonier N, Schmitt E, Parcellier A, Cathelin D, Garrido C, Chauffert B, Solary E, Bonnotte B and Martin F: $\mathrm{CD} 4+\mathrm{CD} 25+$ regulatory $\mathrm{T}$ cells suppress tumor immunity but are sensitive to cyclophosphamide which allows immunotherapy of established tumors to be curative. Eur J Immunol 34: 336-344, 2004.

36. Marchioni M, Cindolo L, Autorino R, Primiceri G, Arcaniolo D, De Sio M and Schips L: High Neutrophil-to-lymphocyte ratio as prognostic factor in patients affected by upper tract urothelial cancer: A systematic review and Meta-analysis. Clin Genitourin Cancer 15: 343-349.e1, 2017.

37. Li X, Ma X, Tang L, Wang B, Chen L, Zhang F and Zhang X: Prognostic value of neutrophil-to-lymphocyte ratio in urothelial carcinoma of the upper urinary tract and bladder: A systematic review and meta-analysis. Oncotarget 8: 62681-62692, 2016.

38. Wu S, Zhao X, Wang Y, Zhong Z, Zhang L, Cao J, Ai K and $\mathrm{Xu}$ R: Pretreatment Neutrophil-Lymphocyte ratio as a predictor in bladder cancer and metastatic or unresectable urothelial carcinoma patients: A pooled analysis of comparative studies. Cell Physiol Biochem 46: 1352-1364, 2018.

39. Faria SS, Fernandes PC Jr, Silva MJ, Lima VC, Fontes W, Freitas-Junior R, Eterovic AK and Forget $P$ : The neutrophil-to-lymphocyte ratio: A narrative review. Ecancermedicalscience 10: 702, 2016.

40. Sacdalan DB, Lucero JA and Sacdalan DL: Prognostic utility of baseline neutrophil-to-lymphocyte ratio in patients receiving immune checkpoint inhibitors: A review and meta-analysis. Onco Targets Ther 11: 955-965, 2018.

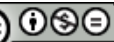

This work is licensed under a Creative Commons Attribution-NonCommercial-NoDerivatives 4.0 International (CC BY-NC-ND 4.0) License. 